\title{
Kinetics of Desulfurization and Oxidation of Molten Nickel-Cobalt Sulfide in the Temperature Range between 1473 and $1673 \mathrm{~K}$
}

\author{
By Teruo Tanabe*, Katuhito Kanzaki**, Masanori Kobayashi*** \\ and Zenjiro Asaki*
}

\begin{abstract}
Molten samples of mixed nickel-cobalt sulfide were oxidized at 1473, 1573 and $1673 \mathrm{~K}$ in a slender alumina tube of 3 $\mathrm{mm} \mathrm{ID} \mathrm{and} 25 \mathrm{~mm}$ length. The sulfur atomic fraction in the mixed sulfide was 0.403 and 0.316 at an atomic Ni/Co ratio of 9. The metal ratio was also varied on the tie line between $\mathrm{Co}_{4} \mathrm{~S}_{3}$ and $\mathrm{Ni}_{3+x} \mathrm{~S}_{2}(x=1.67)$. The mass change of samples and $\mathrm{SO}_{2}$ concentration in the exit gas were measured continuously. The formed oxide was examined with SEM, EPMA and X-ray diffraction.

Desulfurization took place when the sulfur potential of the melt was high; the sample mass decreased with the evolution of $\mathrm{SO}_{2}$ gas. The desulfurization rate was controlled by gas diffusion in the alumina tube. The maximum amount of mass decrease of the sample increased with $\mathrm{Ni}$ concentration in the sulfide. When the sulfur potential of the melt was lowered due to the desulfurization, the metals were oxidized to form a mixed $\mathrm{Ni}$-Co oxide on the melt surface without the evolution of $\mathrm{SO}_{2}$ gas. The growth rate of the oxide layer was controlled by the diffusion of $\mathrm{Ni}$ and Co through the oxide layer. The parabolic rate constant varied with the concentration profile of metals in the oxide, with an activation energy of $170 \mathrm{~kJ} \cdot \mathrm{mol}^{-1}$ for the sample B $(61.7 \mathrm{at} \% \mathrm{Ni}, 6.8$ at $\%$ Co and 31.5 at $\% \mathrm{~S})$.
\end{abstract}

(Received November 9, 1989)

Keywords: oxidation, kinetics, desulfurization, nickel sulfide, cobalt sulfide, molten sulfide, gaseous diffusion, solid diffusion, parabolic rate constant, uphill-diffusion

\section{Introduction}

The direct conversion of molten nickel sulfide to metallic nickel at higher temperature has been commercially operated. On the other hand, the possibility of the formation of metallic nickel by the mutual reaction of molten nickel sulfide and solid nickel oxide under a reduced pressure was suggested by Prasad et al. ${ }^{(1)}$ and Yokoyama et al. ${ }^{(2)}$ However, the reaction mechanism is much complicated. Cobalt is, on the other hand, frequently associated with nickel ores, and it is important to elucidate the oxidation mechanism of the mixed Ni-Co sulfides.

In the previous work ${ }^{(3)}$, the molten nickel sulfide and cobalt sulfide were oxidized separately at $1473 \mathrm{~K}$ as a first step of investigation, and it was reported that the desulfurization took place when the sulfur potential of the melt was higher. When the $\mathrm{SO}_{2}$ partial pressure on the sulfide melts was lowered due to the desulfurization, the formation of the oxide layer of $\mathrm{Ni}$ or Co was formed on the melt surface and the evolution of $\mathrm{SO}_{2}$ gas ceased. It was also reported that the equilibrium $\mathrm{SO}_{2}$ partial pressure on the melt at the transition point from the desulfurization to the oxide formation was almost the same for both sulfides.

* Department of Metallurgy, Kyoto University, Kyoto 606, Japan.

** Former Undergraduate Student, Kyoto University. Present address: Fujitu Ltd., Osaka 540, Japan.

*** Undergraduate Student, Kyoto University, Kyoto 606, Japan.
It is intended in this work to study the oxidation behavior of the mixture of molten $\mathrm{Ni}$ and Co sulfides in the temperature range between 1473 and $1673 \mathrm{~K}$, in succession to the previous work.

\section{Experimental}

\section{Sample preparation}

The $\mathrm{Co}_{4} \mathrm{~S}_{3}$ and $\mathrm{Ni}_{3+x} \mathrm{~S}_{2}$ were synthesized by heating weighed amounts of Co powder of $99.99 \%$ purity and distilled sulfur of $99.999 \%$ purity and $\mathrm{Ni}$ powder of 99.99\% purity and the distilled sulfur in evacuated quartz tubes at $1470 \mathrm{~K}$ for $7 \mathrm{ks}$. The obtained lumps of $\mathrm{Co}_{4} \mathrm{~S}_{3}$ and $\mathrm{Ni}_{3+x} \mathrm{~S}_{2}$ were crushed and the mixed Ni-Co sulfide was prepared by heating a mixture of weighed amount of $\mathrm{Co}_{4} \mathrm{~S}_{3}$ and $\mathrm{Ni}_{3+x} \mathrm{~S}_{2}$ in an evacuated quartz tube. The compositions of the sulfide samples employed in this work are listed in Table 1: The atomic $\mathrm{Ni} / \mathrm{Co}$ ratio of the samples A and B is 9 and the samples B, C, D, M and $\mathrm{N}$ are on the tie line between $\mathrm{Co}_{4} \mathrm{~S}_{3}$ and $\mathrm{Ni}_{3+x} \mathrm{~S}_{2}$

Table 1 Composition of Samples (unit: at\%).

\begin{tabular}{cccc}
\hline Sample & Ni & Co & S \\
\hline A & 53.6 & 5.8 & 40.6 \\
B & 61.7 & 6.8 & 31.5 \\
C & 25.7 & 38.5 & 35.8 \\
D & 18.1 & 42.3 & 39.6 \\
M & 0 & 57.1 & 42.9 \\
N & 71.5 & 0 & 28.5 \\
\hline \hline
\end{tabular}


$(x=1.67)$ in a composition diagram of $\mathrm{Ni}-\mathrm{Co}-\mathrm{S}$.

\section{Experimental procedure}

The experimental apparatus and the procedure were described in the previous paper ${ }^{(3)}$. An alumina tube of 50 mm ID was used for a reaction tube. An amount of 100 $\mathrm{mg}$ of the sulfide sample was put in an alumina tube of 3 $\mathrm{mm}$ ID and $25 \mathrm{~mm}$ length and it was hung in a hot zone of the furnace from an automatic microbalance with using platinum and quartz fibres. It was heated in an $\mathrm{Ar}$ gas stream of a flow rate of $1 \times 10^{-5} \mathrm{~m}^{3} \cdot \mathrm{s}^{-1}$. The furnace temperature was measured by a $\mathrm{Pt} / \mathrm{Pt}-13 \% \mathrm{Rh}$ TC placed just below the sample tube. The depth of molten sulfide in the alumina tube was about $3 \mathrm{~mm}$. When the sample was heated up to a predetermined temperature, the oxidation was started by switching the Ar gas stream to an $\mathrm{O}_{2}-\mathrm{Ar}$ gas mixture.

The oxidation was carried out at 1473, 1573 and 1673 $\mathrm{K}$. The oxygen partial pressure in the $\mathrm{O}_{2}-\mathrm{Ar}$ gas stream was varied from 5 to $50 \mathrm{kPa}$. The time variation of the sample mass and $\mathrm{SO}_{2}$ concentration in the exit gas was continuously measured during the oxidation by the automatic microbalance and an infrared gas analyser, respectively. Microscopic and SEM observations were made on a cross section of the sample after the reaction. Oxidation products were identified by powder X-ray diffraction using Co-K $\alpha$ radiation, and the concentration profile of elements on a cross section of the sample was determined with EPMA.

\section{Results and Discussion}

\section{Progress of oxidation of samples $A$ and $B$ at $1473 \mathrm{~K}$}

Figure 1 shows the time variation of sample mass and $\mathrm{SO}_{2}$ concentration in the exit gas during the oxidation of the sample A (40.3 at $\% \mathrm{~S})$ at $1473 \mathrm{~K}$ under a partial pressure of oxygen of 5 to $50 \mathrm{kPa}$. In the early stage of oxidation, $\mathrm{SO}_{2}$ gas evolved and the sample mass decreased linearly with time. The rate of mass decrease increased with the oxygen partial pressure. The broken lines shown in the figure are the calculated values which will be described later. Subsequently, the evolution of $\mathrm{SO}_{2}$ gas ceased and the sample mass turned to increase. The maximum amount of mass decrease was smaller at higher oxygen partial pressure. When the oxygen partial pressure was $5 \mathrm{kPa}$, an appreciable amount of $\mathrm{SO}_{2}$ gas continued to evolve for over $8 \mathrm{ks}$ and the mass increase was not observed even at a time of $10 \mathrm{ks}$.

The results for the sample B $(31.6$ at $\% \mathrm{~S})$ are shown in Fig. 2. Except for $5 \mathrm{kPa}$ of oxygen partial pressure, the sample mass increased from the start of oxidation, which is quite contrast to the sample A. A very small amount of $\mathrm{SO}_{2}$ gas evolved at first and no $\mathrm{SO}_{2}$ gas was detected thereafter. When the oxygen partial pressure was $5 \mathrm{kPa}$, the mass decreased initially with an evolution of $\mathrm{SO}_{2}$ gas and then turned to increase.

Thus it can be said that the oxidation behavior strong-

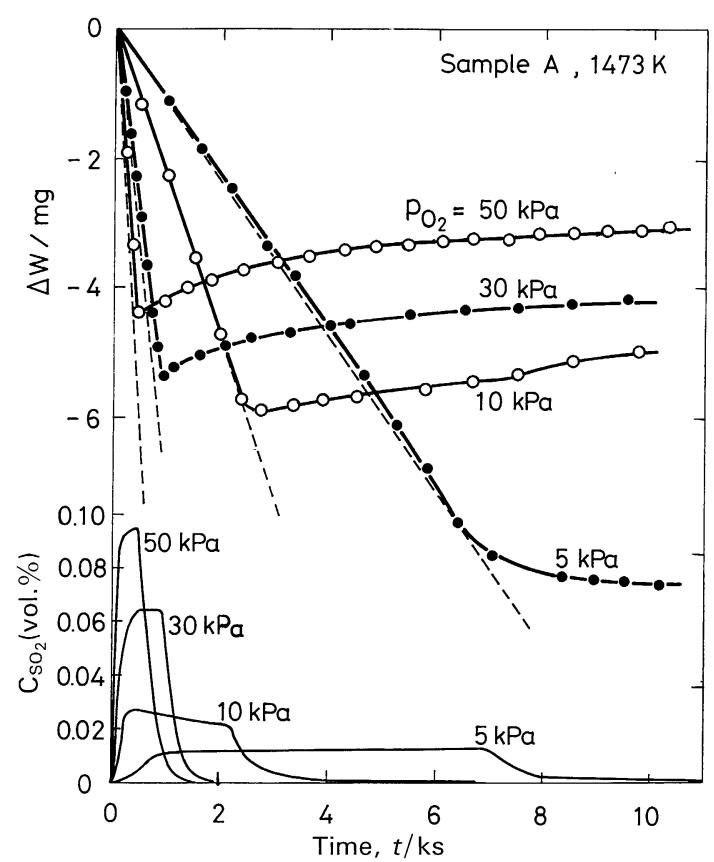

Fig. 1 Mass change of sample $\mathrm{A}$ and evolution of $\mathrm{SO}_{2}$ gas during oxidation at $1473 \mathrm{~K}$.

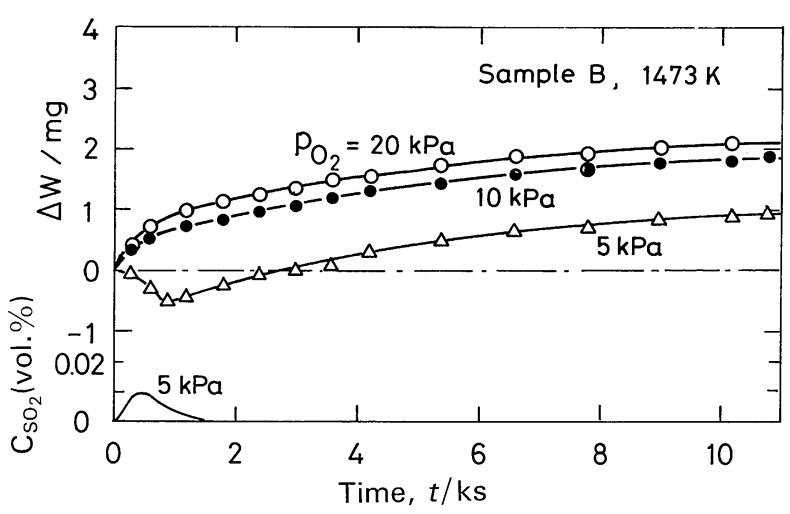

Fig. 2 Mass change of sample B during oxidation at $1473 \mathrm{~K}$.

ly depends on the composition of the sulfide melt. The cross sections of the samples A and B are demonstrated in Fig. 3; 3(a) shows the sample oxidized at $1473 \mathrm{~K}$ for $0.6 \mathrm{ks}$ under $10 \mathrm{kPa}$ of oxygen partial pressure which corresponds to the stage of mass decrease, and 3(b) and 3(c) indicate the samples of which oxidation was stopped in the stage of mass increase. These photos indicate that an oxide layer is formed on the surface of the sulfide melt in the stage of mass increase and no oxide is observed in the stage of mass decrease.

The formed oxide was identified as $\mathrm{NiO}$ and $\mathrm{CoO}$ by powder X-ray diffraction. Figure 4 illustrates the line analysis of elements with EPMA for the sample shown in Fig. 3(b). Thus the dense layer formed on the sulfide melt was a mixed Ni-Co oxide. The concentration of $\mathrm{Co}$ in the oxide layer increased in a direction from the sulfide/oxide interface to the oxide/gas interface and that of Ni decreased inversely: This suggests "uphilldiffusion" of Co and the observation that the concentration of $\mathrm{Co}$ in the oxide is much higher than in the sulfide 

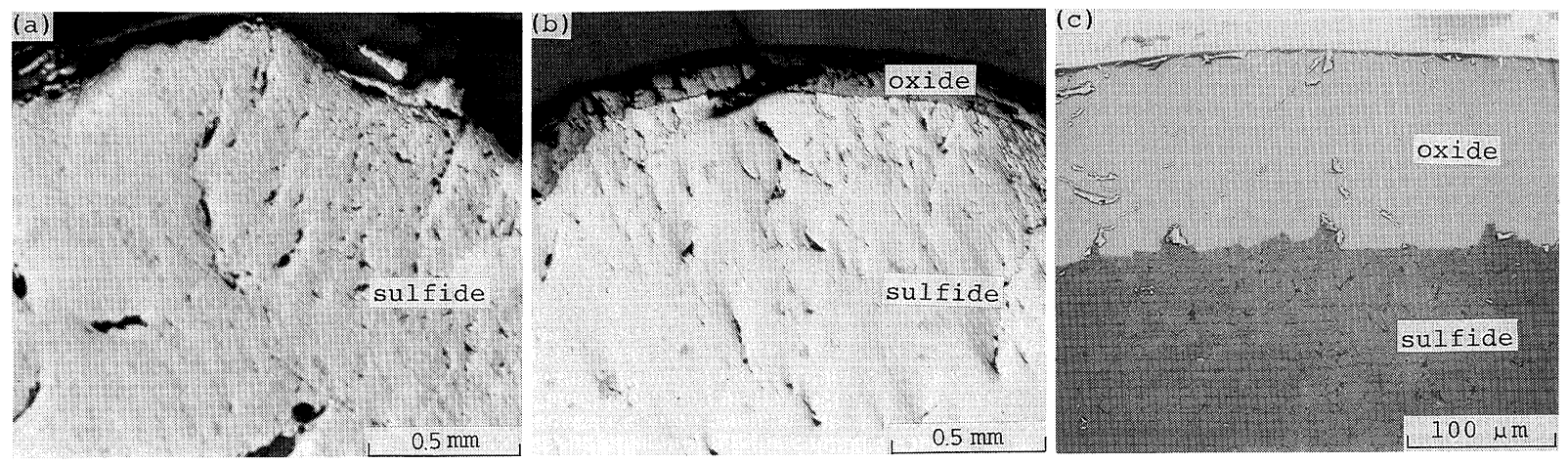

Fig. 3 Cross sections of samples oxidized at $1473 \mathrm{~K}$ at $p_{\mathrm{O}_{2}}=10 \mathrm{kPa}$ : (a) sample A oxidized for $0.6 \mathrm{ks}$, (b) sample A for $10 \mathrm{ks}$ and (c) AEI photograph of sample B oxidized for $10.8 \mathrm{ks}$.

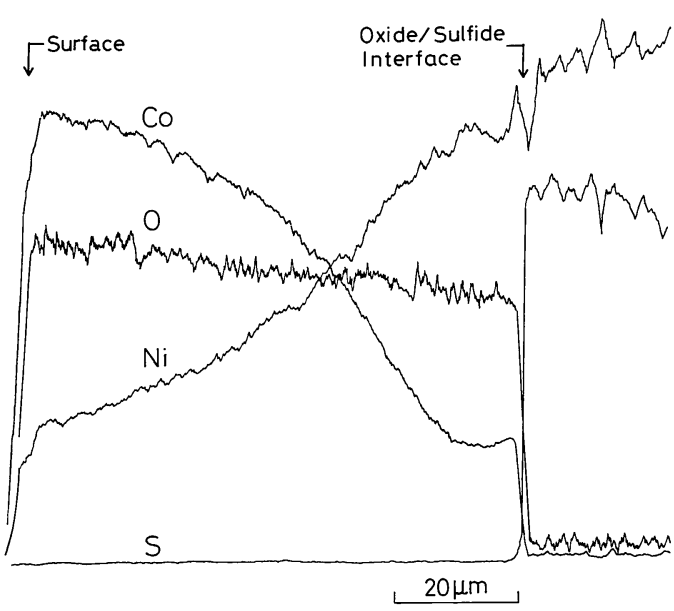

Fig. 4 EDX line analysis of elements along cross section of sample A oxidized at $1473 \mathrm{~K} .\left(p_{\mathrm{O}_{2}}=10 \mathrm{kPa}\right.$, reaction time $\left.=10 \mathrm{ks}\right)$

indicates a preferential oxidation of Co.

From the examination described above, the reaction of mass decrease with the evolution of $\mathrm{SO}_{2}$ gas is thought to be desulfurization without the formation of oxide and it is written as follows.

$$
\mathrm{S}(\text { in melt })+\mathrm{O}_{2}=\mathrm{SO}_{2}
$$

The reaction of mass increase without the evolution of $\mathrm{SO}_{2}$ gas may be due to the formation of mixed $\mathrm{Ni}-\mathrm{Co}$ oxide on the surface of the sulfide melt. Thus the desulfurization takes place in the early stage of oxidation where $\mathrm{S}$ concentration is high in the sulfide melt and subsequently the metals tend to be oxidized to form their oxide at lower sulfur potentials. In the oxidation of the sample B, an oxide layer was formed on the surface of the melt from the start of oxidation, because the initial sulfur concentration of the sulfide melt was low.

\section{Effect of temperature and composition of the melt on oxidation behavior}

The mass change of the sample and $\mathrm{SO}_{2}$ concentration in the exit gas during the oxidation of sample B at 1573 and $1673 \mathrm{~K}$ are shown in Figs. 5 and 6, respectively. The mass decreased linearly with time from the start of oxidation and subsequently it increased with lowering the rate

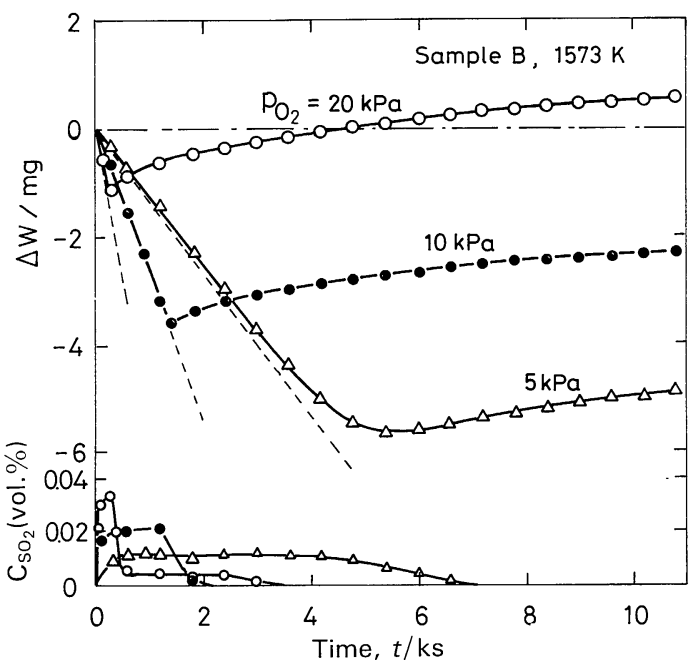

Fig. 5 Mass change of sample $\mathrm{B}$ and evolution of $\mathrm{SO}_{2}$ gas during oxidation at $1573 \mathrm{~K}$.

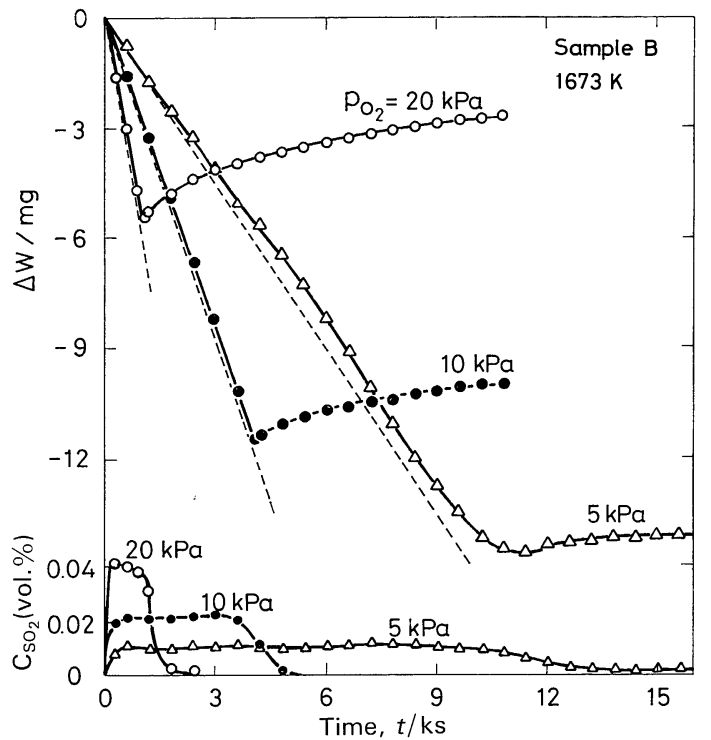

Fig. 6 Mass change of sample $\mathrm{B}$ and evolution of $\mathrm{SO}_{2}$ gas during oxidation at $1673 \mathrm{~K}$.

of $\mathrm{SO}_{2}$ gas evolution. This oxidation behavior is quite different from that at $1473 \mathrm{~K}$ shown in Fig. 2. Though the 

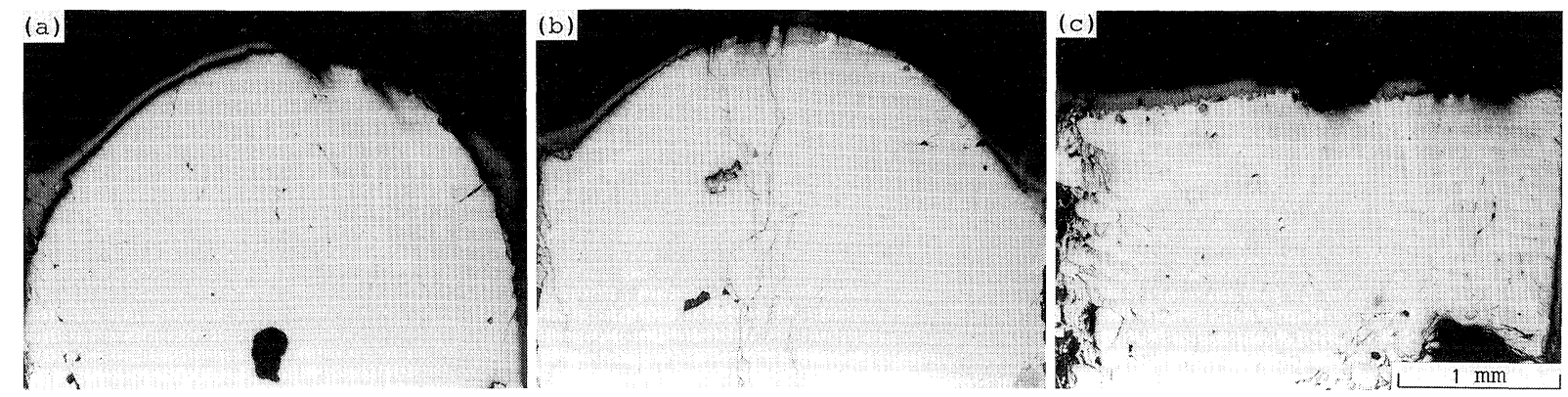

Fig. 7 Cross sections of sample B; oxidized at (a) $1473 \mathrm{~K}$, (b) $1573 \mathrm{~K}$ and (c) $1673 \mathrm{~K}$.

temperature dependence of the rate of mass decrease was not appreciable and the maximum amount of mass decrease increased with temperature.

Figure 7 demonstrates the cross section of the sample B oxidized at 1473,1573 and $1673 \mathrm{~K}$ for $10 \mathrm{ks}$ under the oxygen partial pressure of $10 \mathrm{kPa}$. It is seen in these photographs that a shape of the melt surface is convex upward at 1473 and $1573 \mathrm{~K}$ and it seems rather plane at $1673 \mathrm{~K}$, indicating that the surface tension of the sulfide melt decreases considerably with temperature.

The measured mass and the $\mathrm{SO}_{2}$ concentration for the samples $\mathrm{C}, \mathrm{D}, \mathrm{M}$ and $\mathrm{N}$ oxidized at $1673 \mathrm{~K}$ are shown in Fig. 8, together with that for the sample B. The higher the $\mathrm{Ni}$ concentration in the sulfide, the more the amount of sample mass decrease in the early stage of oxidation. In the oxidation of the sample $\mathrm{D}$, the rate of mass decrease was slightly lower than the theoretical straight line and the transition from mass decrease to mass increase occurred rather gradually. The sample $M$ of the binary Co-S system exhibited a small amount of mass in-

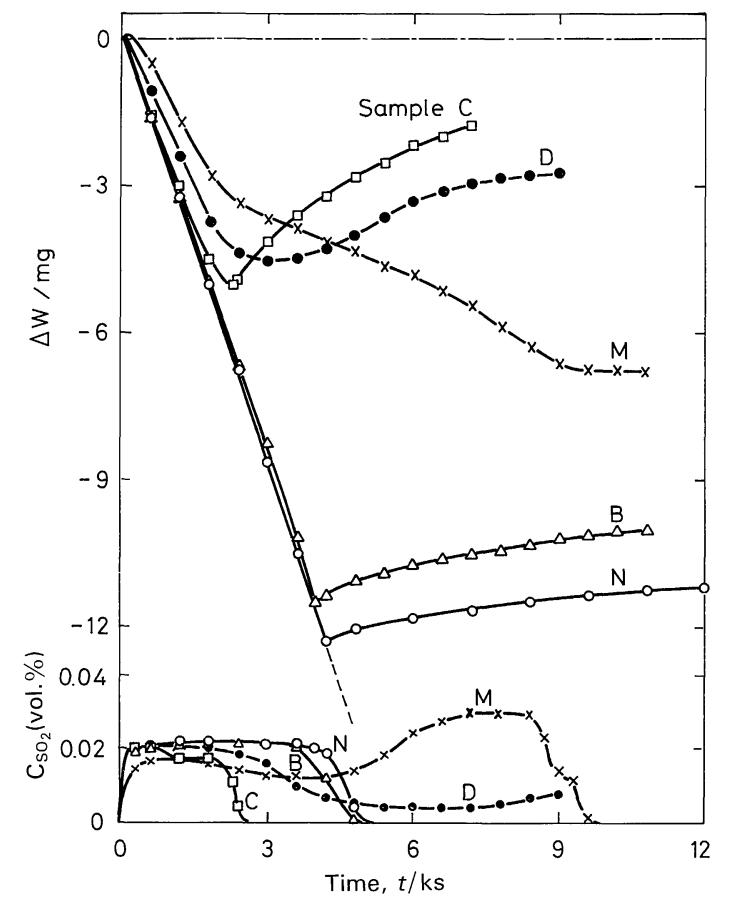

Fig. 8 Mass change and evolution of $\mathrm{SO}_{2}$ gas in the oxidation of samples $\mathrm{B}, \mathrm{C}, \mathrm{D}, \mathrm{M}$ and $\mathrm{N}$ at $1673 \mathrm{~K} .\left(p_{\mathrm{O}_{2}}=10 \mathrm{kPa}\right)$ crease for an initial $100 \mathrm{~s}$ and subsequently the mass decreased. The deviation from the theoretical line of mass decrease seemed large and the concentration of $\mathrm{SO}_{2}$ gas became higher in the later stage of oxidation though the rate of mass decrease was lower than in the early stage.

Under the presumption that the measured mass decrease is due to the progress of the reaction (1), the composition of molten sulfide at the point of minimum mass was calculated and shown by open circles in Fig. 9, except for the sample $M$. It is seen in this figure that the extent of the progress of desulfurization increases with the Ni concentration in the sulfide. We can suppose from this result that direct smelting of the mixed sulfide may be more difficult than single sulfide of $\mathrm{Ni}$.

\section{The rate of desulfurization}

During the progress of the desulfurization reaction (1), counter diffusion of $\mathrm{O}_{2}$ and $\mathrm{SO}_{2}$ gases takes place between an open end of the alumina tube and the melt surface; $\mathrm{O}_{2}$ gas diffuses downward and $\mathrm{SO}_{2}$ gas upward through the gas phase in the alumina tube. On the assumption that overall rate of desulfurization is controlled by this diffusional process, the rate of mass decrease can be calculated as follows:

Under the conditions that

$$
N_{\mathrm{SO}_{2}}=-N_{\mathrm{O}_{2}}, \quad N_{\mathrm{Ar}}=0
$$

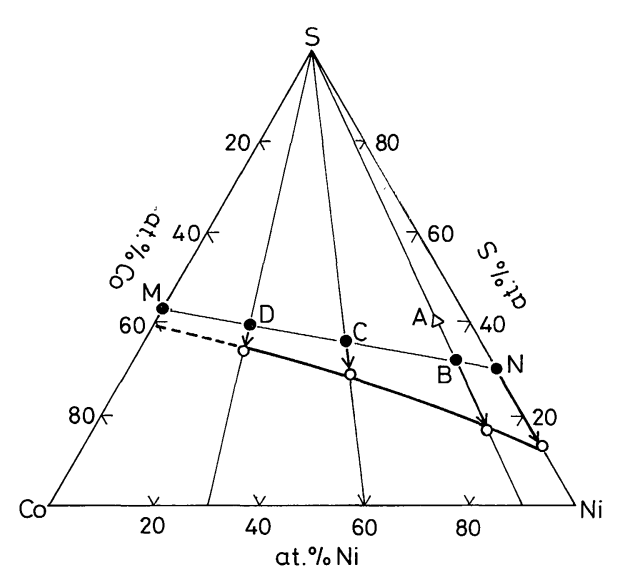

Fig. 9 Compositional change of sulfides during desulfurization at $1673 \mathrm{~K}$; close and open circles denote initial composition and composition at minimum mass, respectively. $\left(p_{\mathrm{O}_{2}}=10 \mathrm{kPa}\right)$ 
and

$$
y_{\mathrm{O}_{2}}=0 \quad \text { (at the melt surface), }
$$

the following equation can be obtained as ${ }^{(4)}$

$$
\begin{aligned}
y_{\mathrm{O}_{2}}= & -\left(S_{1} / S_{2}\right) y_{\mathrm{Ar}_{(0)}}\left\{1-\exp \left(N_{\mathrm{O}_{2}} S_{2} L / c\right\}\right. \\
& +y_{\mathrm{O}_{2(0)}}-L N_{\mathrm{O}_{2}} /\left(c D_{\mathrm{SO}_{2}-\mathrm{O}_{2}}\right)
\end{aligned}
$$

where

$$
S_{1}=1 / D_{\mathrm{SO}_{2}-\mathrm{O}_{2}}-1 / D_{\mathrm{O}_{2}-\mathrm{Ar}}
$$

and

$$
S_{2}=1 / D_{\mathrm{SO}_{2}-\mathrm{Ar}}-1 / D_{\mathrm{O}_{2}-\mathrm{Ar}} \text {. }
$$

This equation can be solved numerically for the flux of oxygen, $N_{\mathrm{O}_{2}}$. The numerical values for $D_{\mathrm{O}_{2}-\mathrm{Ar}}$ was taken from an experimental result ${ }^{(5)}$ and those for $D_{\mathrm{SO}_{2}-\mathrm{O}_{2}}$ and $D_{\mathrm{SO}_{2} \text {-Ar }}$ were estimated from the Chen-Othmer equation ${ }^{(6)}$. The rate of the sample mass decrease is expressed with using $\mathrm{N}_{\mathrm{O}_{2}}$;

$$
\frac{\mathrm{d} \Delta W}{\mathrm{~d} t}=-\pi r^{2} M_{\mathrm{S}} N_{\mathrm{O}_{2}}
$$

The calculated results are shown in Figs. 1, 2, 5 and 6 by broken lines. As seen in these figures, except only for the sample $M$, the calculated results are in good agreement with the observations.

Thus it can be concluded that the rate of desulfurization was controlled by gaseous diffusion in the alumina tube under the present experimental condition. As described before, the amount of mass decrease of the sample $\mathrm{M}$ at $1673 \mathrm{~K}$ was smaller than the theoretical value. The similar results were also observed in the oxidation of binary Co-S melt at $1473 \mathrm{~K}^{(3)}$. It was observed that the melt crept along the wall of the alumina tube up to over $20 \mathrm{~mm}$ from the bottom of the tube. The formation of oxide might take place on the tube wall during the desulfurization of the melt in the bottom of the tube.

\section{The oxidation rate of metals}

As described in III-1 and -2, a mixed Ni-Co oxide layer was formed on the surface of the sulfide melt in the stage of mass increase during the oxidation. Therefore, this may lead to such possibility that the oxidation rate is controlled by solid-phase diffusion through the oxide layer. The amount of mass gain was plotted against the square root of time after the minimum point of sample mass in Fig. 10. The surface area of molten sulfide, $S$, used in the calculation of mass gain was estimated by

$$
S=\pi\left(r^{2}+h^{2}\right)
$$

where $r$ and $h$ are inner radius of the alumina tube and height of the convexed surface of the melt, respectively. Good linearity was obtained as seen in this figure, and the parabolic rate constant, $k_{\mathrm{p}}$, was calculated from the slope of the straight lines.

The Arrhenius plot of the obtained $k_{\mathrm{p}}$-values is demonstrated in Fig. 11, together with those obtained in the oxidation of the systems $\mathrm{Co}-\mathrm{S}$ and $\mathrm{Ni}-\mathrm{S}^{(3)}, \mathrm{Ni}_{3} \mathrm{~S}_{2}-$ $10 \% \mathrm{Co}_{9} \mathrm{~S}_{8}{ }^{(7)(8)}$, metallic $\mathrm{Ni}^{(9)}$ and $\mathrm{Co}^{(10)}$. It is seen that the

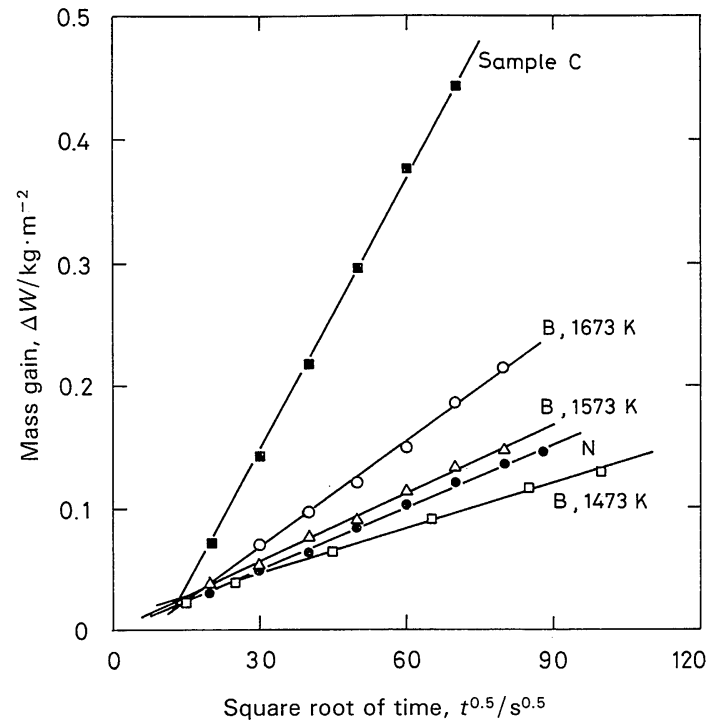

Fig. 10 Parabolic plot of mass gain; time was measured from the point of minimum mass.

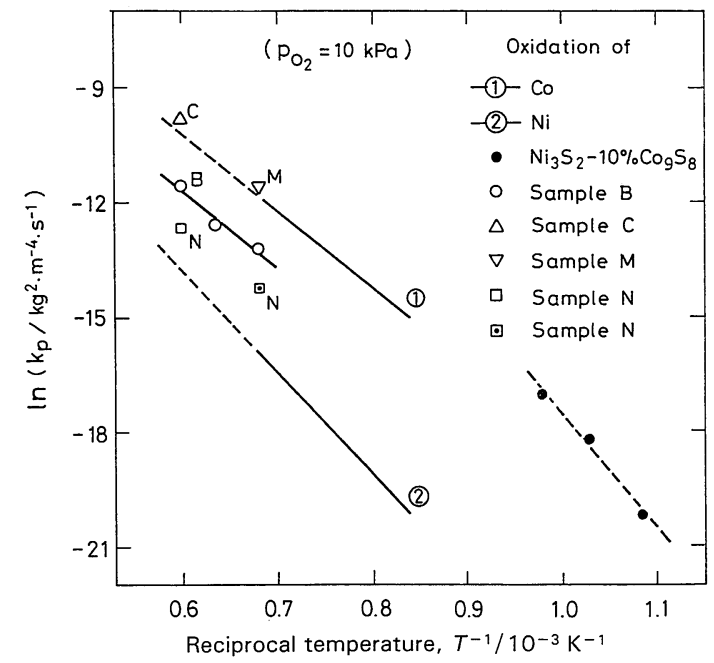

Fig. 11 Arrhenius plot of parabolic rate constant for oxide formation. $\left(p_{\mathrm{O}_{2}}=10 \mathrm{kPa}\right)$

value obtained for the sample of the system $\mathrm{Ni}-\mathrm{S}$ is close to the reported value for the oxidation of metallic $\mathrm{Ni}$. The values for the sample $\mathrm{C}$ of which Co-concentration was 38.5 at $\%$ and for the sample $M$ of the system Co-S were almost the same as the reported value for the oxidation of metallic Co. Moreover, the $k_{\mathrm{p}}$-values for the sample B of which Co-concentration was 6.8 at $\%$ lie between the values for metallic $\mathrm{Ni}$ and $\mathrm{Co}$. The activation energy for the sample B was obtained as $170 \mathrm{~kJ} \cdot \mathrm{mol}^{-1}$.

It was reported ${ }^{(11)}$ that the growth rate of the oxide layer considerably varied with the concentration of $\mathrm{Ni}$ and $\mathrm{Co}$ in the oxidation of Ni-Co alloy. Line analysis of the metal concentrations through the oxide layer was conducted with EPMA. The atomic fraction of Co in the oxide was shown in Fig. 12 against the normalized thickness of the oxide layer. It is seen in this figure that the variation in the atomic fraction of Co for the sample B due to the reaction temperature is minor and that the Co frac- 


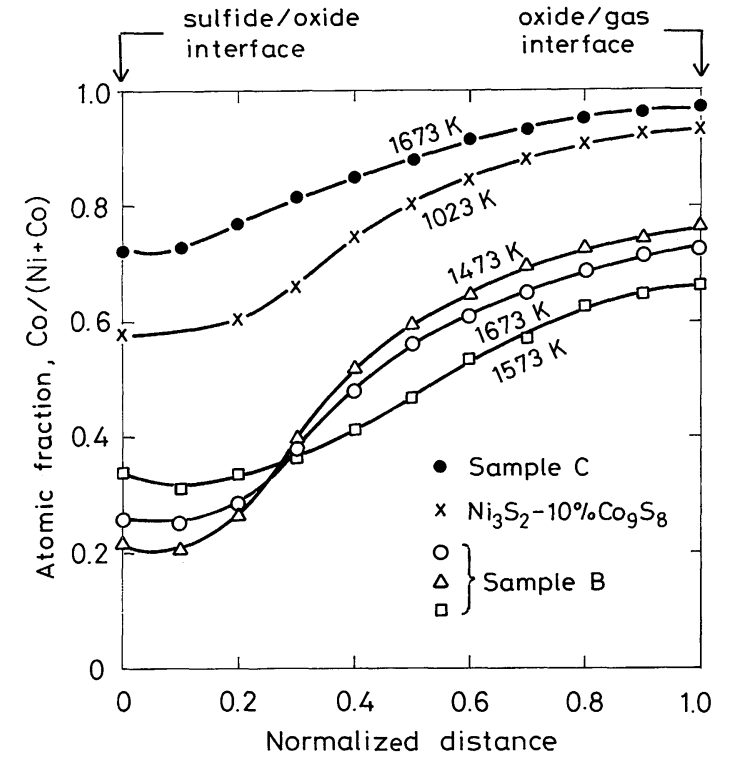

Fig. 12 Concentration profile of cobalt in mixed Ni-Co oxides. $\left(p_{\mathrm{O}_{2}}=10 \mathrm{kPa}\right)$

tion in the oxide layer of the sample $\mathrm{C}$ and in the oxide layer formed on the solid sulfide surface oxidized at 1023 $K^{(7)(8)}$ are much higher than for the sample $B$.

Thus it may be concluded that the growth rate of the oxide layer increases with the Co concentration in the oxide. The concentration profile of $\mathrm{Co}$ in the oxide layer which suggests the "uphill-diffusion" of Co was already analysed by using the Wagner's theory in the previous papers $^{(7)(8)}$

\section{Conclusion}

Molten Ni-Co sulfides of various compositions were oxidized in a mixed $\mathrm{O}_{2}-\mathrm{Ar}$ gas stream at temperatures between 1473 and $1673 \mathrm{~K}$. The results are summarized as follows:

(1) In the oxidation of molten Ni-Co mixed sulfide, desulfurization took place when the sulfur potential of the melt was high. The desulfurization rate was controlled by gas diffusion in the alumina tube.

(2) The maximum amount of mass decrease of the sample due to the desulfurization decreased with oxygen partial pressure in the mixed $\mathrm{O}_{2}-\mathrm{Ar}$ gas stream and increased with the temperature. Moreover, the amount of the mass decrease increased with the $\mathrm{Ni}$ concentration in the melt.
(3) When the sulfur potential of the melt was lowered due to the desulfurization, the metals were oxidized to form a mixed $\mathrm{Ni}-\mathrm{Co}$ oxide on the melt surface. The "uphill-diffusion" of cobalt occurred in the oxide layer.

(4) The growth rate of the oxide layer was controlled by diffusional process of $\mathrm{Ni}$ and $\mathrm{Co}$ through the layer and the parabolic rate constant was varied with the composition of the oxide.

\section{Acknowledgments}

The authors express their hearty thanks to Mr. T. Unesaki, Kyoto University, for his help in measurement with EPMA.

\section{Nomenclature}

$c$ : total concentration of gas phase $\left[\mathrm{mol} \cdot \mathrm{m}^{-2} \cdot \mathrm{s}^{-1}\right]$

$D_{\mathrm{i}-\mathrm{j}}$ : binary diffusion coefficient

$$
\text { (i, } \left.\mathrm{j}=\mathrm{O}_{2}, \mathrm{SO}_{2}, \mathrm{Ar}\right) \quad\left[\mathrm{m}^{2} \cdot \mathrm{s}^{-1}\right]
$$

$h$ : height of convexed sulfide surface [m]

$L:$ distance from open end of tube to melt surface

$M_{\mathrm{s}}$ : molar mass of sulfur

[m]

$N_{\mathrm{i}}$ : flux of species i $\left(\mathrm{i}=\mathrm{O}_{2}, \mathrm{SO}_{2}, \mathrm{Ar}\right) \quad\left[\mathrm{mol} \cdot \mathrm{m}^{-2} \cdot \mathrm{s}^{-1}\right]$

$r$ : inner radius of alumina tube $\quad[=1.5 \mathrm{~mm}]$

$t:$ time

$\Delta W$ : mass change

[s]

$y_{\mathrm{i}}$ : mole fraction of species $\mathrm{i}\left(\mathrm{i}=\mathrm{O}_{2}\right.$, Ar)

$[\mathrm{kg}]$ subscript

(O): open end of alumina tube

\section{REFERENCES}

(1) P. M. Prasad and P. K. Jena: Metall. Trans., 2 (1971), 1651.

(2) K. Yokoyama, K. Tozawa and A. Yazawa: Bull. Res. Inst. Min. Dress. Metall., Tohoku Univ., 31 (1975), 1.

(3) Z. Asaki, H. Abe, K. Murata and Y. Kondo: Trans. JIM, 29 (1988), 60.

(4) Z. Asaki, S. Ando and Y. Kondo: Metall. Trans. B, 19B (1988), 47.

(5) F. Ajersch and J. M. Toguri: Metall. Trans. 3 (1972), 2187.

(6) N. H. Chen and D. F. Othmer: J. Chem. Eng. Data, 7 (1962), 37.

(7) T. Tanabe, T. Mitarai, Z. Asaki and Y. Kondo: J. Japan Inst. Metals, 49 (1985), 633.

(8) T. Tanabe, T. Mitarai, Z. Asaki and Y. Kondo: Trans. JIM, 28 (1987), 299.

(9) C. J. Rosa: Corros. Sci., 22 (1982), 1081.

(10) S. Mrowec and K. Przybylski: Oxid. Metals, 11 (1977), 365.

(11) B. D. Bastow, D. P. Whittle and G. C. Wood: Corros. Sci. 16 (1976), 57. 